\title{
Proteasome inhibitor sensitizes oral squamous cell carcinoma cells to TRAIL-mediated apoptosis
}

\author{
SAYAKA YOSHIBA, MASAYASU IWASE, SAYAKA KURIHARA, MAKIKO UCHIDA, \\ YUJI KURIHARA, HITOSHI WATANABE and SATORU SHINTANI \\ Department of Oral and Maxillofacial Surgery, Showa University School of Dentistry, \\ 2-1-1 Kitasenzoku, Ota-ku, Tokyo 145-8515, Japan
}

Received August 5, 2010; Accepted November 4, 2010

\section{DOI: $10.3892 /$ or.2010.1127}

\begin{abstract}
Oral squamous cell carcinoma (OSCC) cells are relatively resistant to tumor necrosis factor-related apoptosisinducing ligand (TRAIL)-mediated apoptosis during culture. We investigated the role of a proteaosome inhibitor in the survival and apoptosis of these cells. We found that the proteasome inhibitor MG132 markedly accelerated TRAILmediated apoptosis in OSCC cell lines HSC-2 and HSC-3. Addition of TRAIL to MG132-treated cells resulted in Bid cleavage. Furthermore, the inhibitors of caspase-3, caspase- 8 and caspase- 9 reduced the accelerative effect of MG132 on TRAIL-mediated apoptosis. These results suggest that the pro-apoptotic effect of a proteasome inhibitor on TRAILmediated apoptosis may contribute to both extrinsic and intrinsic pathways. MG132 enhanced the expression of the TRAIL receptors DR4 and DR5, and neutralization of DR5 receptors showed a marked reduction of TRALL-mediated apoptosis, whereas that of DR4 was a partial reduction. MG132 also markedly reduced cellular FLICE-inhibitory protein (c-FLIP), cellular inhibitor of apoptosis protein-1 (cIAP-1), X-linked IAP (XIAP) and survivin. Therefore, MG132 provides partial regulation of TRAIL-mediated apoptosis in OSCC cells via modulation of DR5, c-FLIP, cIAP-1, XIAP and survivin. The proteasome inhibitor MG132 may therefore represent a novel strategy for overcoming resistance to TRAIL-mediated apoptosis in OSCC cells.
\end{abstract}

\section{Introduction}

Tumor necrosis factor (TNF)-related apoptosis-inducing ligand (TRAIL) is a death protein that belongs to the TNF superfamily and was originally identified on the basis of

Correspondence to: Dr Sayaka Yoshiba, Department of Oral and Maxillofacial Surgery, Showa University School of Dentistry, 2-1-1 Kitasenzoku, Ota-ku, Tokyo 145-8515, Japan

E-mail: yoshiba@dent.showa-u.ac.jp

Key words: apoptosis, cellular FLICE-inhibitory protein, proteasome inhibitor, oral squamous cell carcinoma, tumor necrosis factorrelated apoptosis-inducing ligand sequence homology to Fas ligand (FasL) and TNF $(1,2)$. TRAIL can induce apoptosis in various tumor cells by engaging the death receptors DR4 and DR5 with subsequent activation of the extrinsic apoptotic pathway $(3,4)$. In the extrinsic pathway, the receptor-mediated activation of caspase- 8 and caspase-10 is followed by the activation of caspase-3, which cleaves intracellular substrates leading to cell death. The intrinsic or mitochondrial pathway is linked to the extrinsic pathway through activated caspase-8, which cleaves Bid and promotes association of Bid with Bax. The Bid/Bax complex induces mitochondrial release of cytochrome c, formation of apoptosomes and activation of caspase-9, followed by activation of executioner caspase-3, caspase- 6 and caspase-7, which again promote cleavage of intracellular protein and cell death (5).

Many tumor cells, including most squamous cell carcinoma (SCC) cells, also express DR4 and DR5 on their surface $(6,7)$. TRAIL receptors are expressed in various cancer and transformed cells as well as normal cells, with little effect on normal cells (7). Thus, TRAIL is an attractive anti-cancer therapeutic target. Preclinical studies in mice and non-human primates have shown that the administration of soluble forms of TRAIL suppressed the growth of TRAIL-sensitive human tumor xenografts with no apparent systemic toxicity $(8,9)$, supporting the potential utility of TRAIL in vivo. Recent studies suggest that TRAIL also effectively promotes apoptosis in primary tumor samples from patients with multiple myeloma and colon carcinoma $(10,11)$.

However, resistance to the TRAIL response has been confirmed in many cancer types including SCC $(5,12-14)$. The initiation of apoptosis is controlled by the integration of both pro-apoptotic and anti-apoptotic signal transduction pathways that mediate stimulation, including signaling through the death receptors $(13,15)$. Although the TRAIL death pathway is clearly defined, no dominant mechanism of resistance to TRAIL-induced cell death has been identified. With respect to the intracellular mechanism, several intracellular anti-apoptotic molecules, including the anti-apoptotic Bcl-2 family, inhibitor of apoptosis protein (IAP) family, and cellular FLICE-inhibitory protein (c-FLIP), inhibit the apoptotic signaling cascade through the inhibition of mitochondrial cytochrome $\mathrm{c}$ release, apoptosome formation and recruitment of procaspase- 8 to the receptor death domain $(16,17)$.

Thus, combination with other agents has been a promising strategy to potentiate the cytotoxicity of TRAIL and its 
therapeutic applications (18-20). Previous studies have shown that various agents, such as chemotherapeutic drugs and growth factor inhibitors, enhance TRAIL-mediated apoptosis against SCC $(7,21,22)$. The ubiquitin-proteasome pathway plays a central role in the regulation of cell cycle control, transcription, signal transduction and apoptosis $(23,24)$. For TRAIL-mediated apoptosis signaling, there are several mechanisms by which apoptosis is regulated by the ubiquitinproteasome pathway $(24,25)$. Therefore, several studies have shown that proteasome inhibitors potently sensitize some cancer cell types to TRAIL-mediated apoptosis. However, it is unclear whether a proteasome inhibitor can modulate TRAIL-mediated apoptosis in OSCC. Strategies to overcome these mechanisms of resistance are the subject of intensive investigation.

In this study, we examined whether proteasome inhibitors could affect the susceptibility of OSCC cells to TRAILmediated apoptosis. In addition, we considered their effect on the expression of TRAIL receptors as well as c-FLIP and the IAP family proteins.

\section{Materials and methods}

Reagents. Recombinant human soluble TRAIL, anti-DR4, anti-DR5 and the MEBCYTO apoptosis kit [employing FITC-conjugated annexin $\mathrm{V}$ and propidium iodide (PI)] were purchased from MBL (Nagoya, Japan). Mouse anti-FLIP monoclonal antibody $(\mathrm{mAb})$ was obtained from Alexis Corp. (Lausanne, Switzerland). We used mAbs against the following: cIAP-1 and XIAP (R\&D Systems Inc., Minneapolis, MN); survivin (Santa Cruz Biotechnology, Santa Cruz, CA); Bid (Cell Signaling Technology, Inc., Danvers, MA). We used caspase inhibitors against the following: caspase-3 (DEVDFMK); caspase-8 (IETD-FMK); and caspase-9 (LEHD-FMK, Trevigen Inc., Gaithersburg, MD). The protease inhibitor MG132 was obtained from Calbiochem (La Jolla, CA). Control antibodies were obtained from Pharmingen (San Diego, CA). TRAIL R1/Fc chimera and R2/Fc chimera proteins were obtained from R\&D Systems, Inc. All other chemicals were of analytical grade

Cell lines and culture conditions. Human oral squamous cell carcinoma (OSCC) cell lines HSC-2 and HSC-3 were obtained from the Japanese Cancer Research Resources Bank (JCRB). Cells were maintained in Dulbecco's modified Eagle's medium supplemented with $10 \%$ heat-inactivated fetal bovine serum, $2 \mathrm{mM}$ L-glutamine, and antibiotics $(100 \mathrm{U} / \mathrm{ml}$ penicillin and $100 \mu \mathrm{g} / \mathrm{ml}$ streptomycin) at $37^{\circ} \mathrm{C}$ in a humidified atmosphere of $5 \% \mathrm{CO}_{2}$.

Cell proliferation assay. The cytotoxic effect of treatment with a proteasome inhibitor and TRAIL on OSCC cells was evaluated by a proliferation assay, in which proliferation was determined using a Cell Counting Kit-8 (Wako, Tokyo, Japan) that labeled cellular DNA with a fluorescent reagent (27). In brief, cells $\left(1 \times 10^{4} /\right.$ well) were seeded into 96 -well plates and cultured for $24 \mathrm{~h}$ to allow adherence. The cells were then incubated for $24 \mathrm{~h}$ at $37^{\circ} \mathrm{C}$ with a range of concentrations of each of the following agents: MG132 (0-100 $\mu \mathrm{M})$ and TRAIL (0-1000 ng/ml). Alternatively, cells were treated with
TRAIL $(200 \mathrm{ng} / \mathrm{ml})$ and MG132 $(1 \mu \mathrm{M})$. After incubation, $10 \mu 1$ of WST-8 (induced by the generation of formazan) was added to each well and incubated for a further $45 \mathrm{~min}$ at $37^{\circ} \mathrm{C}$. Then, the absorbance at $450 \mathrm{~nm}\left(\mathrm{~A}_{450}\right)$ was measured in a microplate reader.

Detection of TRAIL-mediated apoptosis. Annexin V-FITC binding was used as a sensitive method for measuring apoptosis and was performed as described previously $(12,26,27)$. OSCC cells $\left(1 \times 10^{7}\right.$ cells $\left./ \mathrm{ml}\right)$ were preincubated with or without the proteasome inhibitor MG132 (0-10 $\mu \mathrm{M})$ for $2 \mathrm{~h}$. Then, treated OSCC cells $\left(1 \times 10^{6}\right.$ cells $\left./ \mathrm{ml}\right)$ were exposed to TRAIL (200 ng/ml) for $24 \mathrm{~h}$ and then harvested. Specific binding of annexin V-FITC and PI was performed by incubating the culture cells for $15 \mathrm{~min}$ at room temperature in a binding buffer (10 $\mathrm{mM}$ HEPES, $140 \mathrm{mM} \mathrm{NaCl}$ and $2.5 \mathrm{mM}$ $\mathrm{CaCl}_{2}, \mathrm{pH}$ 7.4) containing a saturating concentration of annexin V-FITC according to the manufacturer's instructions. After incubation, the cells were pelleted and analyzed with a FACScan flow cytometer using Cell Quest Software (BectonDickinson Co., Mountain View, CA). Some experiments for TRAIL-mediated apoptosis were performed in the presence of caspase inhibitors $(20 \mu \mathrm{M})$ or neutralizing protein against TRAIL receptors.

Flow cytometric analysis of TRAIL receptor expression. Indirect immunofluorescence analysis of the expression of TRAIL receptor on the cell surface was performed (27). OSCC cells $\left(1 \times 10^{7}\right.$ cells $\left./ \mathrm{ml}\right)$ were incubated with the proteasome inhibitor MG132 (0.4 $\mu \mathrm{M}$ MG132 for HSC-2 cells, $0.8 \mu \mathrm{M}$ MG132 for HSC-3 cells) for $6 \mathrm{~h}$. In brief, after incubation with the reagent, OSCC cells $\left(1 \times 10^{6}\right.$ cells $\left./ \mathrm{ml}\right)$ were treated with a saturating concentration of anti-DR4 or anti-DR5 mAb for $40 \mathrm{~min}$. After washing twice with PBS, an anti-mouse IgG-FITC-conjugated secondary Ab dissolved in phosphate-buffered saline (PBS) containing $0.1 \%$ bovine serum albumin and $0.1 \%$ sodium azide was added for $30 \mathrm{~min}$ at $4^{\circ} \mathrm{C}$. The treated cells were washed once with PBS and then fixed with $1 \%$ paraformaldehyde in PBS. Simultaneous staining was performed with only secondary $\mathrm{Ab}$ as a negative control. The stained cells were analyzed with a FACScan flow cytometer using Cell Quest Software (Becton-Dickinson Co.).

Western blot analysis. The expression of c-FLIP, cIAP-1, XIAP and survivin was identified using Western blot analysis as described previously $(12,26,27)$. OSCC cells $\left(1 \times 10^{7}\right.$ cells/ $\mathrm{ml})$ were preincubated with the proteasome inhibitor MG132 (0.4 $\mu$ M MG132 for HSC-2 cells, $0.8 \mu \mathrm{M}$ MG132 for HSC-3 cells) for $2 \mathrm{~h}$ and exposed to TRAIL (200 $\mathrm{ng} / \mathrm{ml})$ for $24 \mathrm{~h}$. The proteins were separated by a lysis buffer ( $\mathrm{pH}$ 7.4) containing $50 \mathrm{mM}$ Tris- $\mathrm{HCl}, 300 \mathrm{mM} \mathrm{NaCl}, 5 \mathrm{mM}$ EDTA and $0.5 \%$ Triton $\mathrm{X}-100$, with $100 \mathrm{mM}$ sodium o-vanadate and complete mini protease inhibitors (Roche Diagnostics, Mannheim, Germany) after treatment. The lysate was clarified by centrifugation for $15 \mathrm{~min}$ at $14000 \mathrm{x}$ g at $4^{\circ} \mathrm{C}$ and protein concentration was measured by Bradford assay. A $20-\mu \mathrm{g}$ aliquot of protein was loaded and separated by SDS-PAGE, transferred to Hybond PVDF membrane (Amersham Biosciences Corp., Piscataway, NJ), incubated for $90 \mathrm{~min}$ in 5\% skim 
A

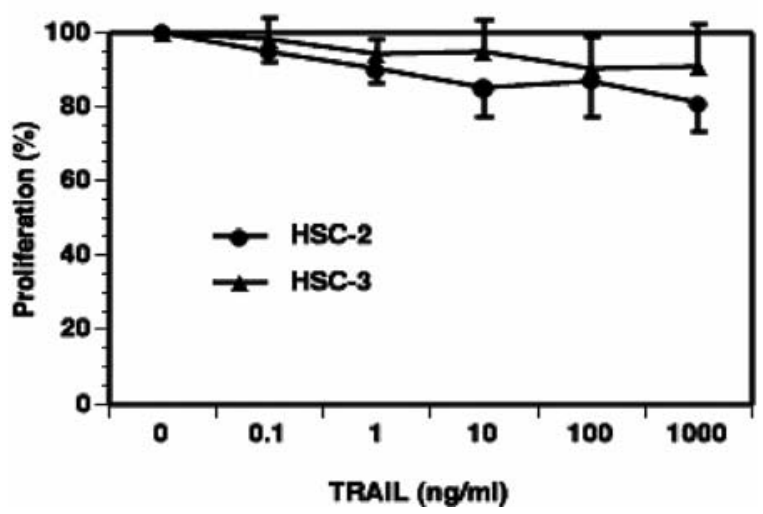

B

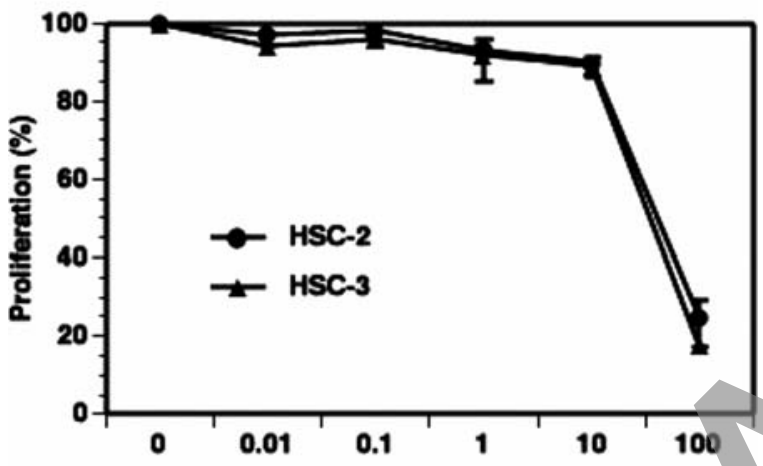

MG132 $(\mu \mathrm{M})$

c

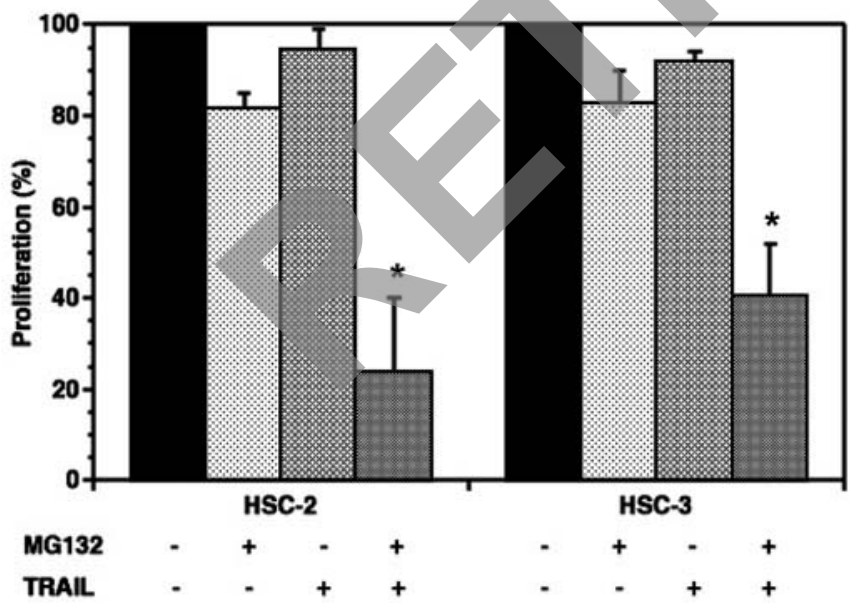

Figure 1. Effects of TRAIL and MG132 on proliferation of HSC-2 and HSC-3 cells. HSC-2 and HSC-3 cells were incubated with (A) TRAIL (0$1000 \mathrm{ng} / \mathrm{ml})$ or (B) MG132 (0-100 $\mu \mathrm{M})$ for $24 \mathrm{~h}$. (C) Bar graph comparing proliferation of HSC-2 and HSC-3 cells treated with or without MG132 $(1 \mu \mathrm{M})$ and TRAIL ( $200 \mathrm{ng} / \mathrm{ml}$ ) for $24 \mathrm{~h}$. Data are expressed as mean $\pm \mathrm{SD}$ of four independent experiments. The asterisk indicates statistically significant differences $(\mathrm{P}<0.05)$ between OSCC treated with MG132, TRAIL or the combination

milk blocking buffer at room temperature, and reacted with primary $\mathrm{Ab}$ (anti-c-FLIP, anti-cIAP-1, anti-XIAP, antisurvivin or anti-Bid) followed by an HRP-conjugated secondary Ab. Protein bands were visualized using electrochemiluminescence and a Western blot detection system (Amersham Biosciences Corp.). B-actin served as an internal control.

Statistical analysis. Values are presented as means \pm SD. Data were analyzed using one-way repeated-measures ANOVA. A level of $\mathrm{P}<0.05$ was considered significant.

\section{Results}

Effects of proteasome inhibitor and TRAIL on proliferation of OSCC cells. To determine whether a proteasome inhibitor or TRAIL could alter the proliferation of OSCC cells, we treated the HSC-2 and HSC-3 cells with a range of concentrations of MG132 (0-100 $\mu \mathrm{M})$ and TRAIL (0-1000 ng/ml). Individually, MG132 and TRAIL did not affect cell proliferation at the experimental concentrations (Fig. 1A and B). We then examined the effects of combination treatment with fixed concentrations of each drug ( $1 \mu \mathrm{M} \mathrm{MG} 132$ with $200 \mathrm{ng} / \mathrm{ml}$ TRAIL). At these concentrations, the proteasome inhibitor and TRAIL alone were not cytotoxic, whereas a significant inhibition of proliferation was observed under the combination treatments (Fig. 1C).

Effects of proteasome inhibitor on TRAIL-mediated apoptosis in OSCC cells. To determine whether the treatment of OSCC cell lines HSC-2 and HSC-3 with a proteasome inhibitor changed their susceptibility to TRAIL-mediated apoptosis, we studied the binding of annexin V of OSCC cells in the presence of TRAIL using a flow cytometer. HSC-2 and HSC-3 cells were relatively resistant to TRAIL-mediated apoptosis. The proteasome inhibitor MG132 produced a dose-dependent enhancement of TRAIL-mediated apoptosis of OSCC cells (Fig. 2A). The effective doses (ED)50 of MG132 for HSC-2 and HSC-3 cells were $\sim 0.4$ and $0.8 \mu \mathrm{M}$, respectively (Fig. 2A). Therefore, the following studies used fixed concentrations of MG132 (0.4 $\mu \mathrm{M}$ MG132 for HSC-2 cells, $0.8 \mu \mathrm{M}$ MG132 for HSC-3 cells) and TRAIL (200 ng/ml). Similarly, spontaneous apoptosis did not appear to be enhanced in proteasome inhibitor-treated OSCC cells by the tested concentrations of the proteasome inhibitor MG132 (Fig. 2B). Apoptosis of OSCC cells was significantly induced by treatment with MG132 and TRAIL in combination but not by treatment with the individual agents (Fig. 2B). Amplification through the mitochondrial pathway is initiated by cleavage of Bid by caspase- 8 and translocation of the truncated $\mathrm{Bid}$ to the mitochondria, leading to Bax/Bakmediated release of cytochrome $\mathrm{c}$ and thereby caspase- 9 activation by Apaf-1. This amplification is required for caspase-3-mediated cellular apoptosis $(4,15)$. Therefore, we also examined whether Bid cleavage occurred in TRAILmediated apoptosis in OSCC cells treated with the proteasome inhibitor. Bid cleavage was strongly advanced by the proapoptotic activity of the proteasome inhibitor compared with the control during TRAIL-mediated apoptosis in OSCC cells (Fig. 2C). These results suggest that the pro-apoptotic effect of the proteasome inhibitor during TRAIL-mediated apoptosis may involve the intrinsic pathway. We next examined whether a caspase inhibitor affected the pro-apoptotic activity of the 
A

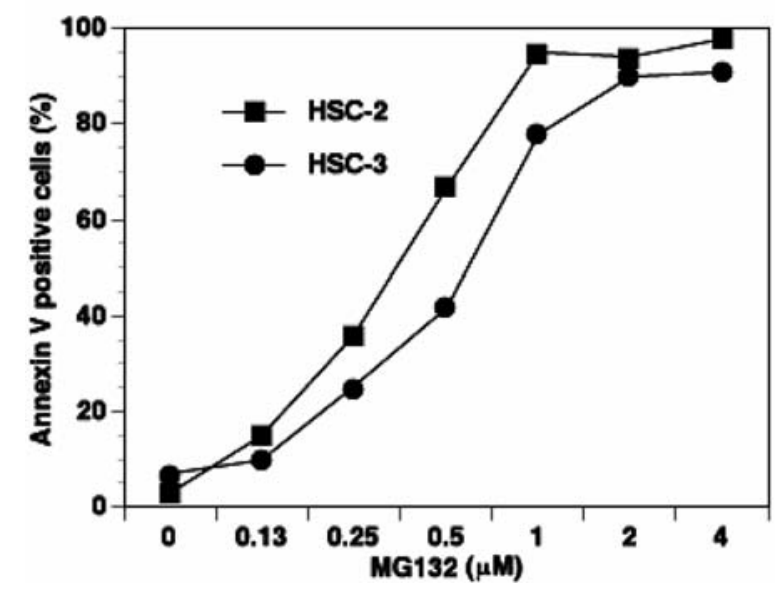

B

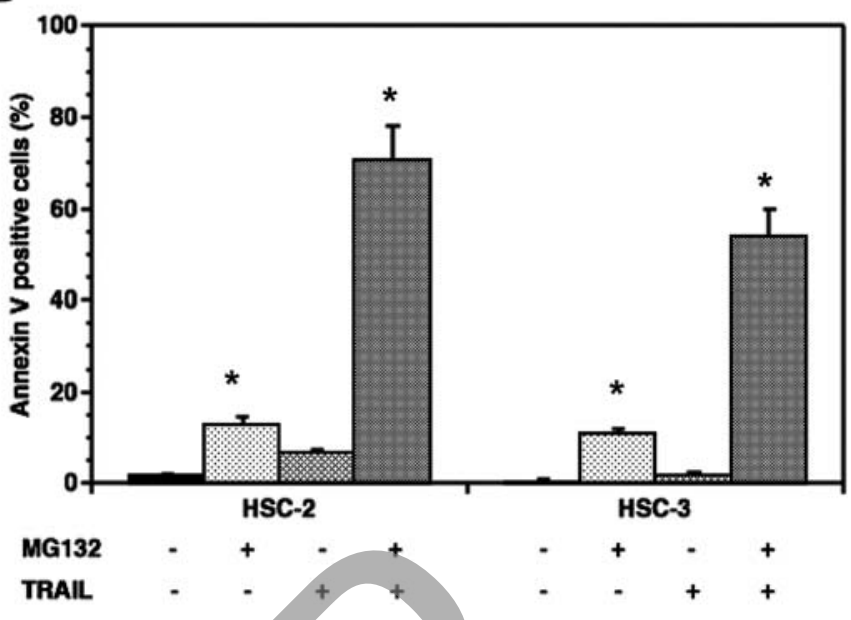

D

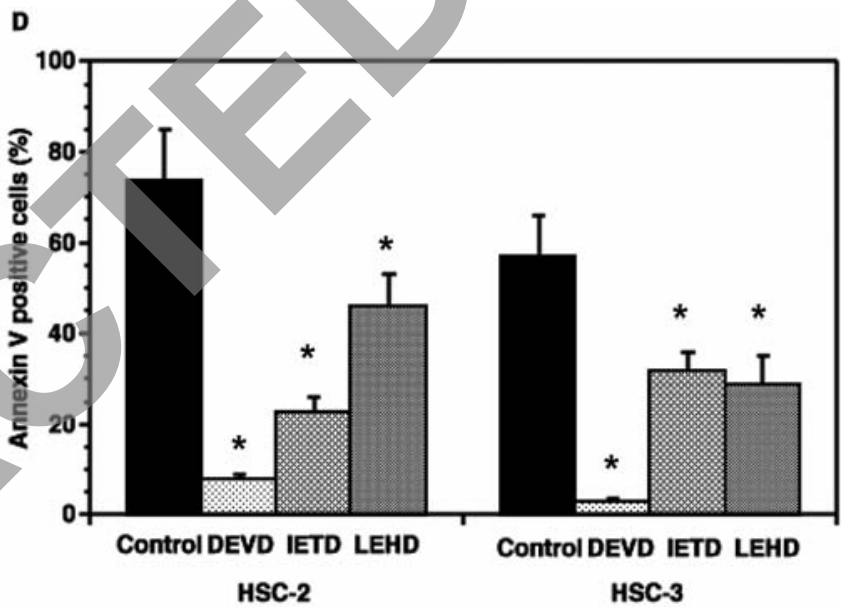

Figure 2. Effects of the proteasome inhibitor MG132 on TRAIL-mediated apoptosis in HSC-2 and HSC-3 cells. (A) HSC-2 and HSC-3 cells were treated with various concentrations of MG132 for $2 \mathrm{~h}$ and then incubated with TRAIL (200 ng/ml) for $24 \mathrm{~h}$. (B) HSC-2 and HSC-3 cells were treated with or without MG132 $(0.4 \mu \mathrm{M}$ for HSC-2, $0.8 \mu \mathrm{M}$ for HSC-3) for $2 \mathrm{~h}$, then incubated with or without TRAIL (200 ng/ml) for $24 \mathrm{~h}$. Data are expressed as mean \pm SD of four independent experiments. (C) Augmentation of TRAIL-mediated Bid cleavage in HSC-2 and HSC-3 cells by the proteasome inhibitor MG132. HSC-2 (left) and HSC-3 (right) cells were treated with or without MG132 $(0.4 \mu \mathrm{M}$ for HSC-2, $0.8 \mu \mathrm{M}$ for HSC-3) for $2 \mathrm{~h}$, then harvested and incubated with TRAIL (200 ng/ml) for $24 \mathrm{~h}$. Bid cleavage was determined using Western blot analysis. All experiments were performed four times independently. (D) HSC-2 and HSC-3 cells were treated with or without MG132 (0.4 $\mu \mathrm{M}$ for HSC-2, $0.8 \mu \mathrm{M}$ for HSC-3) for $2 \mathrm{~h}$, then harvested and incubated for $24 \mathrm{~h}$ with TRAIL (200 ng/ml) and the caspase inhibitors indicated $(20 \mu \mathrm{M})$. Data are expressed as mean \pm SD of four independent experiments. The asterisk indicates statistically significant differences $(\mathrm{P}<0.05)$ between the presence and absence of caspase inhibitors in TRAIL-treated cells.

proteasome inhibitor. We found from these experiments that inhibitors of caspase- 3 , caspase- 8 and caspase- 9 reduced the accelerative effect of the proteasome inhibitor on TRAILinduced apoptosis in OSCC cells (Fig. 2D). These results indicate that the pro-apoptotic action of the proteasome inhibitor was related to both the extrinsic and the intrinsic pathways within the caspase cascade.

Effects of proteasome inhibitor on TRAIL receptor expression in OSCC cells. To investigate the alteration of TRAIL receptor expression in OSCC cells resulting from treatment with a proteasome inhibitor, we examined the TRAIL receptor expression of OSCC cells using a FACScan flow cytometer. TRAIL induces apoptosis by binding to one of its receptors, DR4 or DR5, with subsequent activation of the extrinsic pathway $(4,17)$. The constitutive expression of both TRAIL receptors, DR4 and DR5, was detected on HSC-2 and HSC-3 cells, and we observed marked elevation after addition of the proteasome inhibitor MG132 (Fig. 3A). Therefore, these data indicate that the acceleration of TRAIL-mediated apoptosis observed with proteasome inhibitor treatment was a consequence of increased TRAIL receptor expression. To determine whether DR4 and DR5 can modulate TRAILmediated apoptosis in OSCC cells treated with MG132, we examined the frequency of appearance of apoptotic cells in the presence of neutralizing proteins against TRAIL receptors. The neutralizing protein against DR5 produced a marked reduction of TRAIL-mediated apoptosis in MG132-treated OSCC cells, whereas that against DR4 produced partial inhibition (Fig. 3B).

Effects of proteasome inhibitor on c-FLIP and IAPs in OSCC cells. It is known that the overexpression of c-FLIP is one of the mechanisms of resistance to TRAIL-mediated apoptosis $(4,17)$. To determine whether the expression of c-FLIP in OSCC cells was altered by the treatment with the proteasome inhibitor and TRAIL, we examined the level of c-FLIP using Western blot analysis. Both HSC-2 and HSC-3 cells expressed 
A
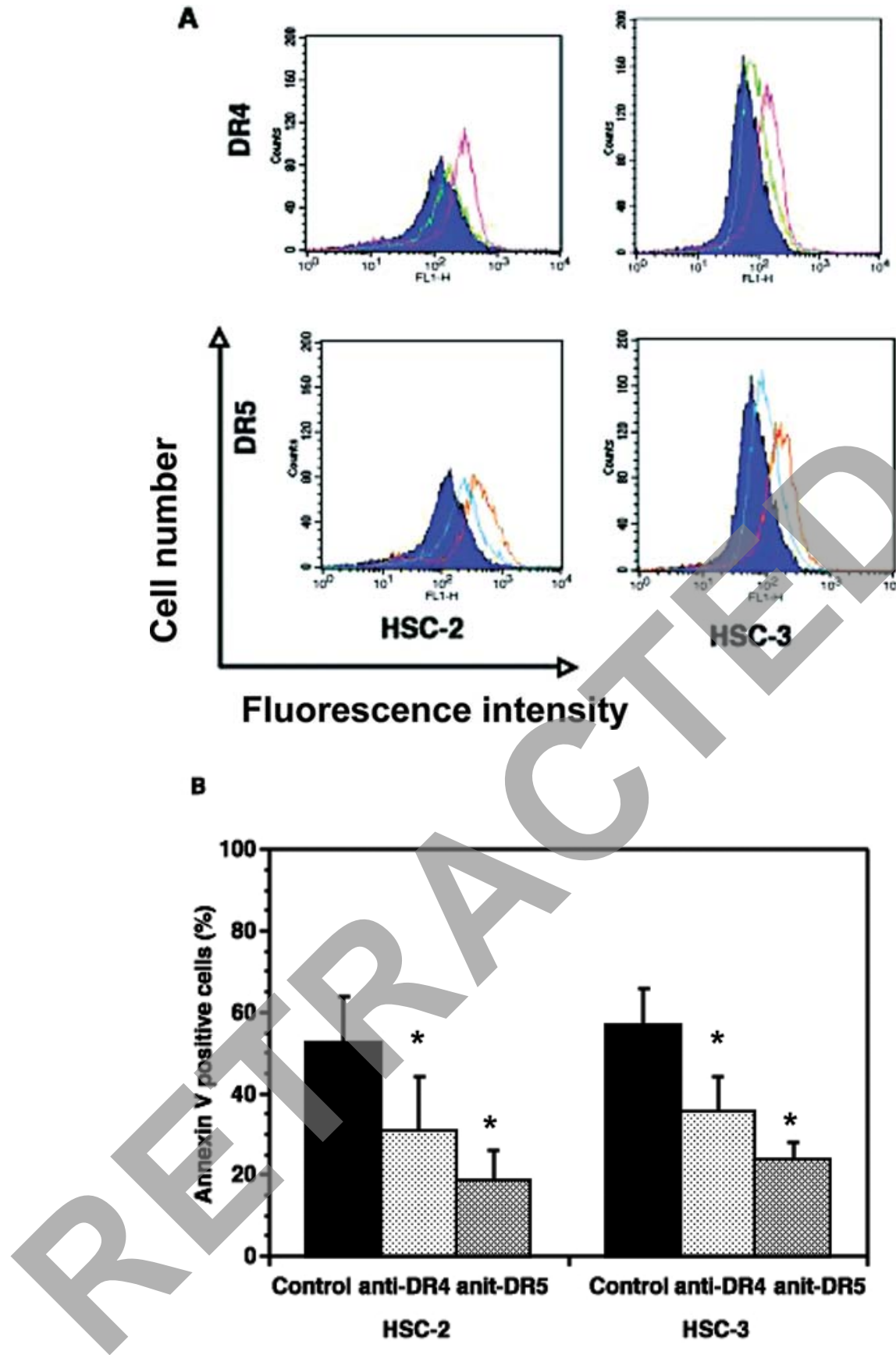

Figure 3. Expression of the TRAIL receptors DR4 and DR5 by HSC-2 and HSC-3 cells treated with the proteasome inhibitor MG132. (A) Representative histograms show the expression of TRAIL receptors in HSC-2 and HSC-3 cells treated with MG132 (0.4 $\mu$ M for HSC-2, $0.8 \mu \mathrm{M}$ for HSC-3) for 12 h, then harvested and assayed for the expression of DR4 and DR5 on the cell membrane. Experiments were performed four times independently. Filled triangles show the untreated controls. Green or blue lines indicate FITC-treated controls, and orange or red lines indicate MG132-treated cells. (B) HSC-2 and HSC-3 cells were treated with MG132 $(0.4 \mu \mathrm{M}$ for HSC-2, $0.8 \mu \mathrm{M}$ for HSC-3) for $2 \mathrm{~h}$ and subsequently incubated with TRAIL in the presence of anti-DR4 (TRAIL DR4/Fc Chimera, $3 \mathrm{ng} / \mathrm{ml}$ ) or anti-DR5 (TRAIL DR5/Fc Chimera, $2 \mathrm{ng} / \mathrm{ml}$ ) neutralizing proteins. Data are expressed as mean \pm SD of four independent experiments. The asterisk indicates statistically significant differences $(\mathrm{P}<0.05)$ between the responses in the presence and absence of anti-TRAIL receptor Abs.

c-FLIP constitutively. When treated with the proteasome inhibitor in the presence of TRAIL, the OSCC cells showed a marked cleavage of c-FLIP protein compared with that observed after treatment with the individual agents (Fig. 4A). These results suggest that the proteasome inhibitor can modulate TRAIL-mediated apoptosis via the down-regulation of c-FLIP expression in OSCC cells.

The IAP family also contributes to the susceptibility to TRAIL-mediated apoptosis $(4,12)$. Therefore, we examined the effects of the proteasome inhibitor on the expression of members of the IAP family, such as cIAP-1, XIA0P and survivin, in OSCC cells. Treatment with the proteasome inhibitor MG132 caused marked cleavage of cIAP-1, XIAP, and survivin during TRAIL-mediated apoptosis (Fig. 4B). We found that the IAP family was significantly downregulated by the combined treatment with MG132 and TRAIL, but not by treatment with the individual agents. These results also suggest that in OSCC cells, the proteasome inhibitor may enhance TRAIL-mediated apoptosis via regulation of the IAP family proteins. 

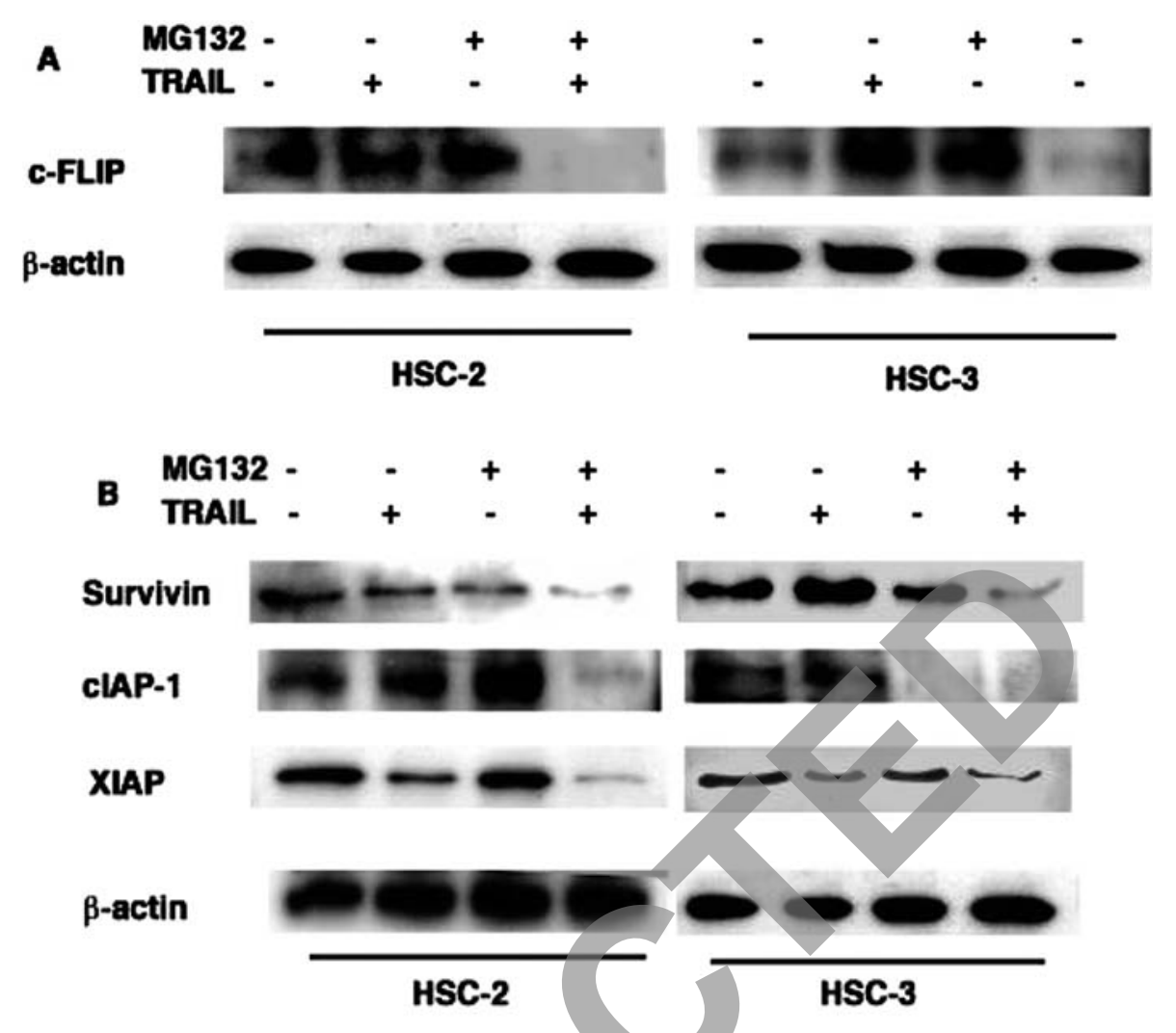

Figure 4. Effects of proteasome inhibitors on expression of c-FLIP and IAPs in HSC-2 and HSC-3 cells. HSC-2 and HSC-3 cells were treated with MG132 $(0.4 \mu \mathrm{M}$ for HSC-2, $0.8 \mu \mathrm{M}$ for HSC-3) for $2 \mathrm{~h}$ and subsequently incubated with TRAIL ( $200 \mathrm{ng} / \mathrm{ml})$ for $24 \mathrm{~h}$. Cells were then harvested, and the expression of c-FLIP (A) and IAPs (B) was determined using Western blot analysis. All experiments were performed four times independently.

\section{Discussion}

OSCC cell lines HSC-2 and HSC-3 have been shown to be resistant to TRAIL-induced apoptosis $(4,12)$. Cancer cells reported to be TRAIL-resistant have been rendered sensitive to TRAIL by co-treatment with a proteasome inhibitor, but it is unknown whether proteasome pathways modulate TRAILmediated apoptosis in SCC cells. We examined the susceptibility of OSCC cells to TRAIL-mediated apoptosis after treatment with a proteasome inhibitor. We demonstrated that treatment of OSCC cells with a proteasome inhibitor significantly enhanced TRAIL-mediated apoptosis. Molecules involved in TRAIL-mediated apoptosis that are regulated by the ubiquitin-proteasome pathway include members of the death receptor, Bcl-2 $(28,29)$, and IAP families $(30,31)$, and inhibitors of $\kappa \mathrm{B}(\mathrm{I} \kappa \mathrm{B})(23,32)$. Furthermore, proteasome inhibitors can also decrease c-FLIP protein levels in cells, resulting in induced apoptosis signaling caused by increased caspase- 8 activation (33-36).

We next studied whether various caspase inhibitors affected the enhancement of the TRAIL-induced apoptosis of OSCC cells by the proteasome inhibitor. We observed that an inhibitor of caspase-3, caspase- 8 or caspase- 9 reduced the accelerative effect of the proteasome inhibitor for TRAILinduced apoptosis in OSCC cells. Furthermore, in proteasome inhibitor-treated OSCC cells, TRAIL-induced apoptosis also enhanced the cleavage of Bid. These results suggest that TRAIL-induced apoptosis in OSCC cells treated with a proteasome inhibitor involves both extrinsic and intrinsic path- ways. Previous studies have shown various mechanisms by which proteasome inhibitors sensitize TRAIL-mediated apoptosis; for example, TRAIL receptors, c-FLIP, the Bcl-2 family, IAP family, NF-кB family and p53 may be involved (24).

In this study, the expression of both TRAIL receptors DR4 and DR5 in OSCC cells was increased by incubation with the proteasome inhibitor. Several studies have shown that proteasome inhibitors increase the expression of death receptors in other solid tumors $(37,38)$. Treatment with the proteasome inhibitor PS-341 increases the expression of DR4 and DR5 in prostate, colon, and bladder cancer cells, and this increase in receptor protein levels is associated with the ubiquitination of the DR5 protein (38). Furthermore, our study showed marked inhibition of TRAIL-mediated apoptosis in MG-132-treated OSCC cells when DR5 protein was neutralized. These results suggest that DR5 is a dominant receptor compared to DR4 for the enhancement of TRAILmediated apoptosis by a proteasome inhibitor. Previous studies also support that DR5 amplifies the apoptotic response of TRAIL induced by proteasome inhibitors in various cancer cells (39). The proteasome inhibitor MG132 increases the DR5 promoter activity of the CCAAT/enhancer-binding protein homologous protein-binding site in prostate cancer cells (40). Treatment with MG132 increases binding of DR5 to the adaptor protein FADD and causes caspase- 8 activation and cleavage of pro-apoptotic Bid in chronic lymphocytic leukemia cells (38). Sensitization produced by the proteasome inhibitor involved the activation of caspase- 8 and caspase- 3 
but not mitochondrial membrane depolarization, suggesting an amplified signaling of the extrinsic cell death pathway. In mice, a proteasome inhibitor combined with DR5 agonist monoclonal antibody reduced lung metastases $(4,41)$.

One of the most proximal regulators of TRAIL-mediated apoptosis is c-FLIP. High levels of c-FLIP have been suggested to correlate with resistance to TRAIL-mediated apoptosis. c-FLIP competitively inhibits the binding of caspase- 8 to the TRAIL receptor complex, thus shutting off the down-stream TRAIL signaling pathway. The expression level of c-FLIP is higher in cancer cells than in cells from normal tissue, and thus cancer cells overcome TRAIL-mediated apoptosis (4). Furthermore, a recent study and our previous study have shown that transfection of oligonucleotide against c-FLIP enhanced apoptosis induced by a death receptor in various cancer cells $(26,27)$. Because a caspase- 8 inhibitor opposed the accelerative effect of proteasome inhibitors on TRAIL-mediated apoptosis, a pro-apoptotic effect of proteasome inhibitors may act upstream of caspase- 8 activation. Previous studies have reported that proteasome inhibitors down-regulate the expression of cFLIP in cancer cells $(36,42)$. MG132 sensitizes TRAILresistant prostate cancer cells by inducing $\mathrm{c}-\mathrm{Fos}$ and repressing c-FLIP. c-Fos, which is activated by MG132, negatively regulates c-FLIP by binding directly to the putative promoter region of the c-FLIP gene (43). It is well known that the intrinsic pathway is regulated by pro- and anti-apoptotic proteins including Bcl-2 and the IAP family $(4,17)$. The IAP family, which includes caspase inhibitors that act predominantly as down-stream inhibitors of TRAIL pathways, has been shown to be highly expressed in various cancer cells, suggesting a key role of the proteins included in this family in preventing apoptosis in cancer cells $(4,17)$. In the present study, OSCC cells showed down-regulation of anti-apoptotic proteins such as cIAP-1, XIAP and survivin in the presence of the proteasome inhibitor and TRAIL. The altered expression of these apoptosis-regulated proteins may also contribute to the enhancement of TRAIL-mediated apoptosis in OSCC cells. Proteasome inhibitors reportedly reduced the expression of anti-apoptotic mediators such as FLIP, Bcl-2, $\mathrm{Bcl}-\mathrm{xL}$ and IAP-1, resulting in the induction of cell death through the mitochondrial apoptotic pathway (44). The proteasome inhibitors MG132 and MG115 also reportedly down-regulated XIAP and survivin in hepatocellular carcinoma cells. MG132 down-regulated phospho-AKT and its downstream target phospho-BAD, indicating that MG132 activated the mitochondrial apoptosis pathway by inhibiting the phosphorylation of AKT and BAD (37).

In conclusion, we found that proteasome inactivation induced TRAIL-mediated apoptosis in OSCC cells through the up-regulation of DR5 and the down-regulation of c-FLIP and IAPs. Therefore, our results support the hypothesis that targeting the ubiquitin-proteasome pathway is a potential strategy for OSCC cells resistant to conventional therapies such as chemotherapy and ionizing radiation or novel therapeutic treatments via death receptors, including Fas and TRAIL. Pharmacologic inhibitors of the ubiquitin-proteasome pathway might achieve this. Recent studies have demonstrated that agonistic mAbs against DR4 and DR5 can induce apoptosis in various cultured and primary cancer cells and may have therapeutic value in cancer (45). Other studies have shown that the anti-tumor effects of anti-human DR4 and DR5 mAbs were synergistically enhanced by combination with chemotherapeutic drugs and radiotherapy $(46,47)$. The present results have important clinical implications in that the use of TRAIL and proteasome inhibitors in combination could prove to be a novel therapeutic strategy for managing TRAIL-resistant tumors.

\section{References}

1. Wiley SR, Schooley K, Smolak PJ, et al: Identification and characterization of a new member of the TNF family that induces apoptosis. Immunity 3: 673-682, 1995

2. Pitti RM, Marsters SA, Ruppert S, Donahue CJ, Moore A and Ashkenazi A: Induction of apoptosis by Apo-2 ligand, a new member of the tumor necrosis factor cytokine family. J Biol Chem 271: 12687-12690, 1996

3. Green DR: Apoptotic pathways: paper wraps stone blunts scissors. Cell 102: 1-4, 2000.

4. Ashkenazi A: Targeting death and decoy receptors of the tumornecrosis factor superfamily. Nat Rev Cancer 2: 420-430, 2002.

5. Younes A and Kadin ME: Emerging applications of the tumor necrosis factor family of ligands and receptors in cancer therapy. J Clin Oncol 21: 3526-3534, 2003.

6. Kondo K, Yamasaki S, Sugie T, et al: Cisplatin-dependent upregulation of death receptor 4 and 5 augments induction of apoptosis by TNF-related apoptosis-inducing ligand against esophageal squamous cell carcinoma. Int J Cancer 118: 230-242, 2006.

7. Kim YH and Lee YJ: Time sequence of tumor necrosis factorrelated apoptosis-inducing ligand (TRAIL) and cisplatin treatment is responsible for a complex pattern of synergistic cytotoxicity. J Cell Biochem 98: 1284-1295, 2006.

8. Ishii M, Iwai M, Harada Y, et al: Soluble TRAIL gene and actinomycin D synergistically suppressed multiple metastasis of TRAIL-resistant colon cancer in the liver. Cancer Lett 245: 134-143, 2007.

9. Dong F, Wang L, Davis JJ, et al: Eliminating established tumor in $\mathrm{nu} / \mathrm{nu}$ nude mice by a tumor necrosis factor-alpha-related apoptosis-inducing ligand-armed oncolytic adenovirus. Clin Cancer Res 12: 5224-5230, 2006.

10. Mitsiades CS, Treon SP, Mitsiades N, et al: TRAIL/Apo2L ligand selectively induces apoptosis and overcomes drug resistance in multiple myeloma: therapeutic applications. Blood 98: 795-804, 2001.

11. Naka T, Sugamura K, Hylander BL, Widmer MB, Rustum YM and Repasky EA: Effects of tumor necrosis factor-related apoptosis-inducing ligand alone and in combination with chemotherapeutic agents on patients' colon tumors grown in SCID mice. Cancer Res 62: 5800-5806, 2002.

12. Uchida M, Iwase M, Takaoka S, et al: Enhanced susceptibility to tumor necrosis factor-related apoptosis-inducing ligandmediated apoptosis in oral squamous cell carcinoma cells treated with phosphatidylinositol 3-kinase inhibitors. Int J Oncol 30: 1163-1171, 2007

13. Wang S and El-Deiry WS: TRAIL and apoptosis induction by TNF-family death receptors. Oncogene 22: 8628-8633, 2003.

14. Takeda K, Stagg J, Yagita H, Okumura K and Smyth MJ: Targeting death-inducing receptors in cancer therapy. Oncogene 26: 3745-3757, 2007

15. Jarpe MB, Widmann C, Knall C, et al: Anti-apoptotic versus pro-apoptotic signal transduction: checkpoints and stop signs along the road to death. Oncogene 17: 1475-1482, 1998.

16. Wang CY, Mayo MW, Korneluk RG, Goeddel DV and Baldwin AS: NF- $\mathrm{B}$ antiapoptosis: induction of TRAF1 and TRAF2 and c-IAP1 and c-IAP2 to suppress caspase-8 activation. Science 281: 1680-1683, 1998.

17. Yagita H, Takeda K, Hayakawa Y, Smyth MJ and Okumura K: TRAIL and its receptors as targets for cancer therapy. Cancer Sci 95: 777-783, 2004

18. Huerta-Yepez S, Vega M, Jazirehi A, et al: Nitric oxide sensitizes prostate carcinoma cell lines to TRAIL-mediated apoptosis via inactivation of NF-kappa B and inhibition of Bcl-xl expression. Oncogene 23: 4993-5003, 2004.

19. Johnstone RW, Frew AJ and Smyth MJ: The TRAIL apoptotic pathway in cancer onset, progression and therapy. Nat Rev Cancer 8: 782-798, 2008. 
20. Gibson SB, Oyer R, Spalding AC, Anderson SM and Johnson GL: Increased expression of death receptors 4 and 5 synergizes the apoptosis response to combined treatment with etoposide and TRAIL. Mol Cell Biol 20: 205-212, 2000.

21. Itashiki Y, Harada K, Ferdous $\mathrm{T}$ and Yoshida H: Effects of tumor necrosis factor-related apoptosis-inducing ligand alone and in combination with fluoropyrimidine anticancer agent, $\mathrm{S}-1$ on tumor growth of human oral squamous cell carcinoma xenografts in nude mice. Anticancer Res 27: 2365-2375, 2007.

22. Teraishi F, Kagawa S, Watanabe T, et al: ZD1839 (Gefitinib, 'Iressa'), an epidermal growth factor receptor-tyrosine kinase inhibitor, enhances the anti-cancer effects of TRAIL in human esophageal squamous cell carcinoma. FEBS Lett 579: 4069-4075, 2005 .

23. Jesenberger V and Jentsch S: Deadly encounter: ubiquitin meets apoptosis. Nat Rev Mol Cell Biol 3: 112-121, 2002

24. Zhang HG, Wang J, Yang X, Hsu HC and Mountz JD Regulation of apoptosis proteins in cancer cells by ubiquitin. Oncogene 23: 2009-2015, 2004.

25. Sayers TJ and Murphy WJ: Combining proteasome inhibition with TNF-related apoptosis-inducing ligand (Apo2L/TRAIL) for cancer therapy. Cancer Immune Immunother 55: 76-84, 2006.

26. Iwase $\mathbf{M}$, Watanabe $\mathrm{H}$, Kondo $\mathrm{G}$, Ohashi $\mathbf{M}$ and Nagumo $\mathbf{M}$ : Enhanced susceptibility of oral squamous cell carcinoma cell lines to FAS-mediated apoptosis by cisplatin and 5-fluorouracil. Int J Cancer 106: 619-625, 2003.

27. Takaoka S, Iwase M, Uchida M, et al: Effect of combining epidermal growth factor receptor inhibitors and cisplatin on proliferation and apoptosis of oral squamous cell carcinoma cells. Int J Oncol 30: 1469-1476, 2007.

28. Tan ML, Ooi JP, Ismail N, Moad AI and Muhammad TS Programmed cell death pathways and current antitumor targets. Pharm Res 26: 1547-1560, 2009.

29. Choi K, Ryu SW, Song S, Choi H, Kang SW and Choi C: Caspase-dependent generation of reactive oxygen species in human astrocytoma cells contributes to resistance to TRAIL mediated apoptosis. Cell Death Differ 17: 833-845, 2010.

30. Leverkus M, Sprick MR, Wachter T, et al: Proteasome inhibition results in TRAIL sensitization of primary keratinocytes by removing the resistance-mediating block of effector caspase maturation. Mol Cell Biol 23: 777-790,2003.

31. Tu SP, Sun YW, Cui JT, et al: Tumor suppressor XIAPAssociated factor 1 (XAF1) cooperates with tumor necrosis factor-related apoptosis-inducing ligand to suppress colon cancer growth and trigger tumor regression. Cancer 116: 1252-1263, 2010

32. Kovalenko A, Chable-Bessia C, Cantarella G, Israël A, Wallach D and Courtois G: The tumour suppressor CYLD negatively regulates $\mathrm{NF}-\mathrm{kappaB}$ signalling by deubiquitination. Nature 424: 801-805, 2003

33. Ryu BK, Lee MG, Chi SG, Kim YW and Park JH: Increased expression of cFLIP(L) in colonic adenocarcinoma. J Pathol 194: 15-19, 2001.

34. Rippo MR, Moretti S, Vescovi S, et al: FLIP overexpression inhibits death receptor-induced apoptosis in malignant mesothelial cells. Oncogene 24: 7753-7760, 2004.
35. Sánchez-Pérez T, Ortiz-Ferrón G and López-Rivas A: Mitotic arrest and JNK-induced proteasomal degradation of FLIP and Mcl-1 are key events in the sensitization of breast tumor cells to TRAIL by antimicrotubule agents. Cell Death Differ 17: 883-894, 2010.

36. Sayers TJ, Brooks AD, Koh CY, et al: The proteasome inhibitor PS-341 sensitizes neoplastic cells to TRAIL-mediated apoptosis by reducing levels of c-FLIP. Blood 102: 303-310, 2003.

37. Inoue $\mathrm{T}$, Shiraki $\mathrm{K}$, Fuke $\mathrm{H}$, et al: Proteasome inhibition sensitizes hepatocellular carcinoma cells to TRAIL by suppressing caspase inhibitors and AKT pathway. Anticancer Drugs 17: 261-268, 2006.

38. Kabore AF, Sun J, Hu X, McCrea K, Johnston JB and Gibson SB: The TRAIL apoptotic pathway mediates proteasome inhibitor induced apoptosis in primary chronic lymphocytic leukemia cells. Apoptosis 11: 1175-1193, 2006.

39. Liu X, Yue P, Chen S, et al: The proteasome inhibitor PS-341 (bortezomib) up-regulates DR5 expression leading to induction of apoptosis and enhancement of TRAIL-induced apoptosis despite up-regulation of c-FLIP and survivin expression in human NSCLC cells. Cancer Res 67: 4981-4988, 2007.

40. Yoshida T, Shiraishi T, Nakata S, et al: Proteasome inhibitor MG132 induces death receptor 5 through CCAAT/enhancerbinding protein homologous protein. Cancer Res 65: 5662-5667, 2005.

41. Shanker A, Brooks AD, Tristan CA, et al: Treating matastatic solid tumors with bortezomib and a tumor necrosis factorrelated apoptosis-inducing ligand receptor agonist antibody. J Natl Cancer Inst 100: 649-662, 2008.

42. Fukazawa T, FujiwaraT, Uno F, et al: Accelerated degradation of cellular FLIP protein through the ubiquitin-proreasome pathway in p53-mediated apoptosis of human cancer cells. Oncogene 20: 5225-5231, 2001

43. Li W, Zhang $X$ and Olumi AF: MG-132 sensitizes TRAILresistant prostate cancer cells by activating c-Fos/c-Jun heterodimers and repressing c-FLIP(L). Cancer Res 67: 2247-2255, 2007.

44. Conticello C, Adamo L, Giuffrida R, et al: Proteasome inhibitors synergize with tumor necrosis factor-related apoptosisinduced ligand to induce anaplastic thyroid carcinoma cell death. J Clin Endocrinol Metab 92: 1938-1942, 2007.

45. Pukac L, Kanakaraj P, Humphreys R, et al: HGS-ETR1, a fully human TRAIL-receptor 1 monoclonal antibody, induces cell death in multiple tumor types in vitro and in vivo. Br J Cancer 92: 1430-1441, 2005

46. Georgakis GV, Li Y, Humphreys R, et al: Activity of selective fully human agonistic antibodies to the TRAIL death receptors TRAIL-R1 and TRAIL-2 in primary and cultured lymphoma cells: induction of apoptosis and enhancement of doxorubicinand bortezomib-induced cell death. Br J Haematol 130: 501-510, 2005.

47. Marini P, Denzinger S, Schiller D, et al: Combined treatment of colorectal tumors with agonistic TRAIL receptor antibodies HGS-ETR1 and HGS-ETR2 and radiotherapy: enhanced effects in vitro and dose-dependent growth delay in vivo. Oncogene 25: 5145-5154, 2006 